\title{
Fármacos de reposicionamiento y fármacos específicos en fase preclínica para la COVID-19
}

\section{Repositioning drugs and specific drugs in preclinical phase for COVID-19}

\author{
Carlos Francisco Cabrera-Sánchez, ${ }^{*}$ J. Yureri Sánchez-Godínez, \\ *Facultad de Estudios Superiores Zaragoza, Universidad Nacional Autónoma de México. Ciudad de México, México; *Facultad de \\ Ciencias, Universidad Nacional Autónoma de México, Ciudad de México, México; §̊nstituto Nacional de Enfermedades Respiratorias \\ Ismael Cosío Villegas, Ciudad de México, México.
}

\begin{abstract}
RESUMEN. El reposicionamiento de fármacos es una actividad que se realiza comúnmente por los laboratorios, y consiste en el uso comercial de un fármaco para un fin distinto para el que fue investigado o aprobado. En 2019 inició la pandemia de la COVID-19 causada por un nuevo virus, el SARS-CoV-2, un virus para el cual la población humana no tiene inmunidad, y tampoco se cuenta con un tratamiento eficaz. Como primera estrategia para tratar a los pacientes gravemente enfermos, se reposicionaron los fármacos que mostraban al menos teóricamente ser efectivos contra el SARS-CoV-2 para uso de emergencia. Una vez que se tuvieron resultados de los estudios clínicos, se evaluó su efectividad en la prevención de casos graves y/o mortales, si el fármaco mostraba una efectividad significativa, la Organización Mundial de la Salud (OMS) emitió la recomendación correspondiente para su uso, de lo contrario se emite la alerta de suspender su uso para la COVID-19. En esta revisión se describen los fármacos que se han reposicionado siguiendo este proceso así como los nuevos fármacos específicos para el SARS-CoV-2 que se encuentran en fase experimental y preclínica.
\end{abstract}

Palabras clave: Reposicionamiento de fármacos, uso de emergencia, COVID-19, SARS-CoV-2.

\section{INTRODUCCIÓN}

El SARS-CoV-2 es el causante de la pandemia que inició en 2019, es un virus nuevo para el cual los humanos no tienen inmunidad, surgió por el salto entre especies (murciélagohumano), y para el cual tampoco se cuenta con un tratamiento efectivo. Debido a la emergencia del SARS-CoV-2 se propuso una serie de fármacos llamados de reposicionamiento para evaluar su efectividad contra el virus por medio de estudios clínicos a nivel global, incluyendo los hospitales de nuestro país.

\begin{abstract}
Drug repositioning is an activity commonly performed by laboratories, and consists of the commercial use of a drug for a different purpose for which it was investigated or approved. In 2009, the COVID-19 pandemic began, caused by a new virus, SARS-CoV-2, a virus for which the human population has no immunity, and for which there is no effective treatment. As a first strategy to treat severely ill patients, drugs were repositioned for emergency use if they were shown to be at least theoretically effective against SARS-CoV-2. Once the results of the clinical studies were available, their effectiveness in preventing severe and/or fatal cases was evaluated. If the drug showed significant effectiveness, the World Health Organization (WHO) issued a recommendation for its use, otherwise a warning was issued to discontinue its use for COVID-19. This review describes the drugs that have been repositioned following this process, as well as the new SARS-CoV-2 specific drugs that are in experimental and preclinical phases.
\end{abstract}

Keywords: Drug repositioning, emergency use, COVID-19, SARS-CoV-2.

Los fármacos de reposicionamiento, también conocidos como la reorientación de fármacos o el reperfilado de fármacos, se definen como la identificación de nuevos usos para fármacos existentes. Su estudio y su uso se han realizado desde hace varias décadas, ya que se reducen los riesgos y costes de desarrollo así como los fallos relacionados con la seguridad, ya que estos fármacos tienen un desarrollo de formulación bien conocido, así como los datos de farmacocinética y farmacodinamia, reduciendo todo el proceso entre tres y 12 años, ${ }^{1}$ por lo que durante

Correspondencia:

\section{Dra. Yolanda González}

Instituto Nacional de Enfermedades Respiratorias Ismael Cosío Villegas, Ciudad de México, México.

Correo electrónico: ygonzalezh@iner.gob.mx

Recibido: 23-VII-2021; aceptado: 21-IX-2021.

Citar como: Cabrera-Sánchez CF, Sánchez-Godínez JY, González Y. Fármacos de reposicionamiento y fármacos específicos en fase preclínica para la COVID-19. Neumol Cir Torax. 2021; 80 (4): 258-268. https://dx.doi.org/10.35366/103451 
la pandemia por la COVID-19 fue la principal estrategia. En situaciones normales se tendría que hacer el estudio previo de reposicionamiento; sin embargo, debido al creciente número de pacientes que enfermaban con gravedad, se aprobó su estudio de emergencia para estos pacientes. ${ }^{1}$

Los fármacos de reposicionamiento en la actualidad son amplios, y entre ellos se encuentra la ivermectina. Es un fármaco antiparasitario que fue aprobado inicialmente en humanos en 1987 para tratar por vía oral la oncocercosis causada por el parásito Onchocerca volvulus. Posteriormente, se han realizado investigaciones para su uso en el tratamiento del cáncer y es uno de los fármacos de emergencia que se utilizó para tratar al SARS-CoV-2 con resultados variables. ${ }^{2}$

Los análisis clínicos se realizan en tiempo real a nivel global, y de acuerdo con estos datos se generan las recomendaciones de su uso, o su desuso con base en su marginal o nula efectividad (por ejemplo, la hidroxicloroquina) y surgen nuevas propuestas de fármacos para su evaluación (como el remdesivir, el plasma de pacientes convalecientes, etcétera). Actualmente continúa este proceso que involucra la evaluación de la efectividad de los fármacos de reposicionamiento, la generación de la información clínica de su eficacia y el surgimiento de las guías para su administración, actualizando los esquemas de tratamiento. Aquí describimos el proceso de reposicionamiento de los principales fármacos autorizados por la OMS, la evaluación de su efectividad y su aprobación para su uso en pacientes con COVID-19. Adicionalmente, describimos los fármacos específicos que se encuentran en fase experimental o fase preclínica contra el SARS-CoV-2.

\section{ESPECTROS CLÍNICOS DE LA COVID-19}

Al igual que en otras enfermedades virales, en la COVID-19 se presenta un espectro de síntomas que va desde asintomáticos hasta enfermedad grave o mortal. La mayoría de los pacientes presentan fiebre (83-99\%), tos (59-82\%), cansancio (44-70\%), anorexia (40-84\%), disnea (31-40\%) y mialgias (11-35\%). También se han descrito otros síntomas inespecíficos como dolor de garganta, congestión nasal, cefaleas, diarrea, náuseas y vómitos. Asimismo, se han descrito anosmia (pérdida del olfato) y ageusia (pérdida del gusto) antes del inicio de los síntomas respiratorios. ${ }^{3}$

Las personas mayores, y los pacientes inmunodeprimidos en particular, pueden presentar síntomas atípicos como cansancio, disminución del estado de alerta, reducción de la movilidad, diarrea, pérdida de apetito, síndrome confusional agudo y ausencia de fiebre. ${ }^{3}$

La clasificación de estos espectros es importante desde el punto de vista farmacológico, ya que dependiendo de su evolución se ajustará el tratamiento requerido. En la
Tabla 1 se muestran de manera general las clasificaciones y el manejo del paciente de acuerdo a la severidad de la enfermedad con base en las guías internacionales y nacionales reportadas. ${ }^{3-5}$

\section{EL SARS-COV-2}

La diferencia con la pandemia de influenza de 2009 es que esta nueva pandemia es causada por un virus para el cual no existe un tratamiento farmacológico específico, ni se contaba con una vacuna, por lo que conocer su estructura y la fisiopatología es esencial para implementar medidas de control con el uso de fármacos de reposicionamiento hasta que se cuente con un fármaco eficaz y específico. El SARS-CoV-2 es un virus que pertenece a la subfamilia coronavirinae en la familia coronaviridae, del linaje $\beta$-coronavirus 2B, el genoma de los CoV (27-32 kb) es un ARN de sentido positivo de una sola cadena (ARNs +), el cual comparte una homología de secuencia de $80 \%$ con el SARS-CoV-1 y una homología de secuencia de 50\% con Middle East Respiratory Syndrome (MERS) - CoV. . $^{6-10}$

En el SARS-CoV-2, la proteína de la nucleocápside (N) formó la cápside fuera del genoma, el genoma está empaquetado en una envoltura que está asociada con tres proteínas estructurales: proteína de membrana (M), glicoproteína de pico o espiga (S) y proteína de envoltura (E).. ,8-10

La entrada de coronavirus en las células huésped está mediada por la proteína S, por lo que es el principal objetivo para los tratamientos antivirales. Para entrar en las células huésped se une al receptor de la enzima convertidora de angiotensina 2 (ACE2) en las células del hospedero a través del dominio de unión al receptor (RBD) siendo este receptor otro blanco terapéutico importante. ${ }^{6,8-10}$

El SARS-CoV-2 infecta las células del hospedero a través de una interacción con la molécula ACE2. La escisión y activación de la proteína de pico o espiga (S) se da a través de la proteasa TMPRSS2, ésta es una proteasa de la célula huésped y es esencial para la entrada viral. A continuación se lleva a cabo un proceso de endocitosis, esta segunda fase permite que el virus entre en la célula huésped y que posteriormente inicie el proceso de replicación y la liberación de los viriones fuera de la célula infectada para infectar nuevas células y así continuar con el ciclo de infección. El SARS-CoV-2 contiene células presentadoras de antígenos (APC), las cuales se adhieren a las células detríticas del huésped, lo que resulta en la activación de los macrófagos con la producción descontrolada de citocinas proinflamatorias (IFN- $\alpha$, IFN- $\gamma$, IL-1 $\beta$, IL-6, IL-12, IL-18, IL-33, TNF- $\alpha$, TGF- $\beta$, etc.) y quimiocinas (CCL2, CCL3, CCL5, CXCL8, CXCL9, CXCL10, etc.), esta reacción es llamada «tormenta de citosinas», la cual deteriora el revestimiento de las células epiteliales y al llegar a la circulación sanguínea causa daño a otros órganos. ${ }^{8-11}$ 


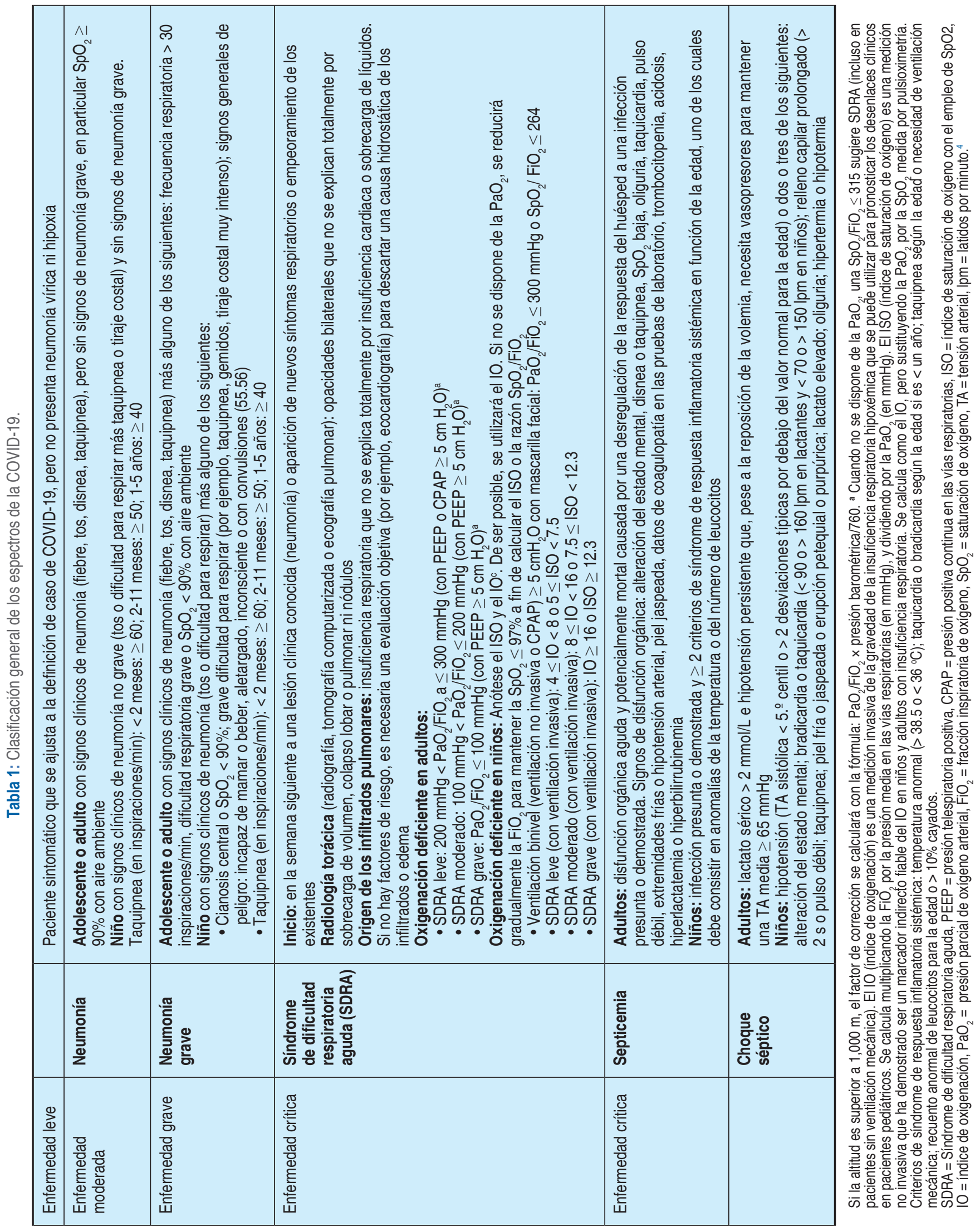




\section{FÁRMACOS DE REPOSICIONAMIENTO Y SU EFECTIVIDAD}

Fármacos que actúan sobre el sistema inmunológico

Anticuerpos neutralizantes

El plasma de pacientes que se han recuperado de COVID19 contiene anticuerpos específicos contra el SARS-CoV-2 que pueden ayudar a neutralizar al virus y modificar la respuesta inflamatoria. ${ }^{12}$

El 23 de agosto de 2020 la Administración de Alimentos y Medicamentos (FDA) emitió una EUA (autorización de uso de emergencia) para plasma de convalecencia para el tratamiento de pacientes hospitalizados con COVID-19 sobre la base de evaluaciones indirectas retrospectivas de la eficacia generada a partir de un gran Programa de Acceso Ampliado (EAP). El EAP permitió el uso de plasma convaleciente independientemente de su título. El panel (NIH) revisó los análisis del EAP y determinó que los datos no eran suficientes para establecer la eficacia o seguridad del plasma de convalecencia COVID-19 debido a posibles factores de confusión, la falta de aleatorización y falta de un grupo de control no tratado. ${ }^{12}$

A nivel nacional, aún no se sabe a ciencia cierta si el plasma convaleciente será un tratamiento efectivo contra COVID-19, pero en estudios de otros países ha resultado efectivo..$^{13}$ Debido a que no hay tratamiento específico para COVID-19, se está permitiendo el uso de emergencia del plasma convaleciente exclusivamente como agente terapéutico en investigación para tratar COVID-19 bajo los lineamientos emitidos por la Secretaría de Salud a través de la colaboración conjunta del Centro Nacional de la Transfusión Sanguínea (CNTS) y la Comisión Federal para la Protección contra Riesgos Sanitarios (COFEPRIS) (Tabla 1). ${ }^{13}$

\section{Bamlanivimab/Etesevimab}

Bamlanivimab (también conocido como LY-CoV555 y LY3819253) es un anticuerpo monoclonal neutralizante que se dirige al dominio de unión al receptor (RBD) de la proteína S del SARS-CoV-2. Etesevimab (también conocido como LY-CoV016 y LY3832479) es otro anticuerpo monoclonal neutralizante que se une a un epítopo en el RBD de la proteína S del SARS-CoV-2.12,14,15

La autorización del uso de emergencia para bamlanivimab + etesevimab se basó en datos de varios estudios, incluido el «bloqueo de la adhesión viral y la entrada de células con anticuerpos neutralizantes del SARS-CoV-2» BLAZE-1 y ensayos BLAZE-4. En el ensayo de fase 3 BLAZE-1, un ensayo aleatorio que incluyó a 1.035 participantes de alto riesgo, el criterio principal de valoración fue la pro- porción de participantes que tuvieron una hospitalización relacionada con COVID-19 (definida como $\geq 24$ horas de cuidados intensivos) o que murieron por cualquier causa antes del día 29. En comparación con los que recibieron placebo, los participantes que recibieron bamlanivimab $2.800 \mathrm{mg}+$ etesevimab $2.800 \mathrm{mg}$ tuvieron $5 \%$ de reducción absoluta y una reducción relativa del $70 \%$ en hospitalizaciones relacionadas con COVID-19 o muerte por cualquier causa (Tabla 1). 12,16,17

\section{Casirivimab/imdevimab}

Casirivimab (anteriormente REGN10933) e imdevimab (anteriormente REGN10987) son anticuerpos monoclonales humanos recombinantes que se unen a epítopos no superpuestos de la proteína S RBD del SARS-CoV-2.12,14,15

La recomendación para el uso de casirivimab + imdevimab se basa en los resultados de la fase 3 del estudio R10933-10987-COV-2067 (la información de este estudio está disponible actualmente sólo en una publicación de prensa, y no hay una preimpresión o publicación revisada por pares). Este ensayo comparó a 1,355 participantes que recibieron casirivimab 1,200 $\mathrm{mg}+$ imdevimab 1,200 mg contra 1,341 participantes que recibieron placebo. Las hospitalizaciones relacionadas con COVID-19 o la muerte por cualquier causa fueron reportadas en 18 de 1,355 participantes (1.3\%) en el brazo de casirivimab + imdevimab y en 62 de 1,341 participantes (4.6\%) en el brazo de placebo $(p<0.0001)$. Esto representa una reducción absoluta de 3.3 y $71 \%$ de reducción relativa de hospitalización o muerte en los participantes del tratamiento con casirivimab + imdevimab. ${ }^{12,18,19}$

Dos productos de anticuerpos monoclonales combinados anti-SARS-CoV-2: bamlanivimab + etesevimab y casirivimab + imdevimab han sido recibidos como uso de emergencia por la Administración de Alimentos y Medicamentos (FDA) para el tratamiento de COVID-19 leve a moderado en pacientes ambulatorios con alto riesgo de progresión. En estudios de laboratorio, algunas variantes del SARS-CoV-2 de interés o preocupación que albergan ciertas mutaciones han reducido notablemente la susceptibilidad a bamlanivimab y pueden tener menor sensibilidad a tesevimab y casirivimab. La susceptibilidad in vitro reducida a ambos anticuerpos en un régimen combinado es actualmente poco común. ${ }^{12,18,19}$

Los pacientes que presentan COVID-19 en su espectro grave, pueden desarrollar una respuesta inflamatoria sistémica que conduce a lesión y disfunción de múltiples órganos. Se ha propuesto que los efectos antiinflamatorios de los corticosteroides podrían prevenir o mitigar estos efectos inflamatorios que causan daño tisular. $^{12}$

La seguridad y eficacia de la terapia combinada de corticosteroides y un agente antiviral dirigido a pacientes 
SARS-CoV-2 para el tratamiento de la COVID-19 no se han estudiado en ensayos clínicos, y existen razones teóricas por las que dicha combinación terapéutica puede ser beneficiosa en pacientes con enfermedad grave. ${ }^{12}$

Las recomendaciones sobre el uso de corticosteroides para COVID-19 se basan en gran medida en datos del RECOVERY trial, un gran ensayo multicéntrico, aleatorizado y abierto realizado en el Reino Unido. Este ensayo comparó pacientes hospitalizados que recibieron hasta 10 días de dexametasona con los que recibieron la atención estándar. La mortalidad a los 28 días fue menor entre los pacientes que fueron aleatorizados a recibir dexametasona que entre los que recibieron la atención estándar. ${ }^{12,20}$

Este beneficio fue observado en pacientes que recibieron ventilación mecánica o requirieron oxígeno suplementario en el momento de la inscripción. No se observó beneficio de la dexametasona en pacientes que no requirieron oxígeno suplementario en el momento de la inscripción. ${ }^{12}$

\section{Dexametasona}

Es un fármaco inhibidor de la síntesis de prostaglandinas y leucotrienos, sustancias que median en los procesos vasculares y celulares de la inflamación y de la respuesta inmunológica. Por tanto, reducen la vasodilatación y el exudado líquido típico de los procesos inflamatorios, la actividad leucocitaria, la agregación y degranulación de los neutrófilos, la liberación de enzimas hidrolíticas por los lisosomas, etcétera. Ambas acciones se deben a la inhibición de la síntesis de fosfolipasa A2, enzima encargada de liberar los ácidos grasos poliinsaturados precursores de las prostaglandinas y leucotrienos. ${ }^{5,21,22}$

Se recomienda bajo estricto seguimiento de control de infecciones y farmacovigilancia, y siempre de acuerdo con los criterios descritos en el estudio original. Para pacientes hospitalizados por infección confirmada por SARS-CoV-2 o con sospecha clínica de COVID-19 que requieran de oxigenación suplementaria o estén en ventilación mecánica. No se indicará en pacientes ambulatorios o en quienes no requieran de oxígeno suplementario. ${ }^{23}$ De manera internacional, las guías de tratamiento para la COVID-19 de la National Institutes of Health $(\mathrm{NIH})$ proponen que de no estar disponible dexametasona, se pueden usar de manera alternativa otros glucocorticoides como prednisona, metilprednisolona o hidroclorotiazida. ${ }^{12}$

\section{Baricitinib}

Es un inhibidor oral de JAK que es selectivo para JAK1 y JAK2 y está aprobado por la FDA para el tratamiento de la artritis reumatoide. Este fármaco puede modular las respuestas inflamatorias posteriores a través de la inhibición de JAK1/JAK2 y ha mostrado una inhibición dependiente de la dosis de STAT3 inducida por IL-6 fosforilación. El baricitinib ha postulado efectos antivirales al bloquear el síndrome respiratorio agudo severo del coronavirus 2 (SARS-CoV-2) de ingresar e infectar las células pulmonares. ${ }^{12}$

El ensayo ACTT-2 multicéntrico, aleatorizado y doble ciego comparó (asignación 1: 1) Baricitinib oral 4 mg al día (hasta 14 días o hasta el alta hospitalaria) versus placebo, ambos administrados en combinación con remdesivir IV (durante 10 días o hasta el alta hospitalaria). En la cohorte general, el tiempo medio de recuperación fue más corto en el grupo de baricitinib más remdesivir (siete días) que en el grupo placebo más remdesivir. La mejora en las categorías ordinales en el día 15 fue un criterio de valoración secundario clave y nuevamente, el baricitinib demostró un beneficio significativo sólo en el subgrupo de pacientes que requerían flujo alto oxígeno o ventilación no invasiva. ${ }^{12}$

El panel (recomendaciones para el tratamiento de la infección por SARS-CoV-2, agente causal de COVID-19) no recomienda el uso de baricitinib, a menos que sea en un ensayo clínico controlado debidamente autorizado por los comités de investigación y de ética en investigación correspondientes debido a su amplio efecto inmunosupresor. ${ }^{23}$

Ruxolitinib

Es un inhibidor oral de JAK selectivo para JAK1 y JAK2 que está aprobado actualmente para mielofibrosis, policitemia vera y enfermedad aguda de injerto contra huésped. Al igual que el baricitinib, puede modular respuestas inflamatorias posteriores a través de la inhibición de JAK1/JAK2 y ha exhibido dosis dependiente inhibición de la fosforilación de STAT3 inducida por IL-6. Ruxolitinib también ha postulado efectos antivirales impidiendo que el SARS-CoV-2 ingrese e infecte las células pulmonares. ${ }^{24}$

Un ensayo de fase 2 pequeño, simple ciego, aleatorizado y controlado en pacientes con COVID-19 en China comparó ruxolitinib $5 \mathrm{mg}$ por vía oral dos veces al día $(\mathrm{n}=20)$ con placebo (administrado como vitamina C 100 mg; n = 21), ambos administrados en combinación con la terapia SOC (control de asistencia estándar). Hubo más pacientes en el grupo con ruxolitinib que en el grupo de placebo que tuvieron una mejoría radiográfica en las exploraciones de tomografía computarizada del tórax en el día 14 (90\% para ruxolitinib frente a $61.9 \%$ para placebo; $p=0.05)$ y un tiempo de recuperación más corto desde la linfopenia inicial (cinco días para ruxolitinib frente a ocho días para placebo; $p=0.03$ ) cuando estaba presente. ${ }^{12}$

En México se llevó a cabo un estudio de un caso clínico de una paciente de 32 años con diagnóstico de neumonía por COVID-19 bajo tratamiento con ruxolitinib por 14 días. Los autores concluyen que ruxolitinib demostró ser una opción segura y eficiente en el manejo del paciente 
Con neumonía por SARS-CoV-2 al limitar el síndrome de liberación de citocinas evidenciado por la evolución clínica y marcadores de inflamación. ${ }^{25}$

\section{Tofacitinib}

Tofacitinib es el inhibidor de JAK prototípico, predominantemente selectivo para JAK1 y JAK3, con una modesta actividad contra JAK2 y como tal, puede bloquear la señalización de las citocinas de cadena gamma (p. ej. IL-2, IL-4) y proteínas gp 130 (p. ej. IL-6, IL-11, interferones). Es un agente oral aprobado por primera vez por la FDA para tratamiento de la artritis reumatoide y se ha demostrado que disminuye los niveles de IL-6 en pacientes con esta enfermedad. ${ }^{11,26}$

Pfizer y BioNTech establecieron recientemente un acuerdo de colaboración para desarrollar conjuntamente una posible vacuna contra la COVID-19, publicando dos nuevos estudios que ayudan a comprender la interacción entre $S$. pneumoniae, el SARS-CoV-2 y los estudios del inhibidor JAK tofacitinib en pacientes con neumonía relacionada con la COVID-19. Un estudio independiente de fase 2 sobre el uso de tofacitinib, un inhibidor oral de Janus, Kinasa (JAK) en pacientes con neumonía intersticial por SARS-CoV-2, está por iniciarse en Italia. El estudio cuenta con el apoyo de una subvención de Pfizer. ${ }^{27}$

Pfizer también está en conversaciones con otras instituciones para discutir sobre otros estudios adicionales que incluyan al tofacitinib y probablemente otros moduladores inmunológicos. Es importante señalar que el tofacitinib no está actualmente aprobado para este uso y no debe utilizarse en pacientes con una infección activa grave. ${ }^{27}$

\section{Acalabrutinib}

Acalabrutinib es un inhibidor de BTK oral de segunda generación que está aprobado por la FDA para tratar las células B neoplasias malignas (es decir, leucemia linfocítica crónica/linfoma de linfocitos pequeños, linfoma de células del manto). Se propone el uso de acalabrutinib en pacientes con COVID-19 porque puede modular la señalización que promueve la inflamación. ${ }^{12}$ Los datos sobre acalabrutinib se limitan a los resultados de una serie de casos retrospectivos de 19 pacientes con COVID-19 grave. La evaluación de los datos para discernir cualquier beneficio clínico está limitada por el pequeño tamaño de la muestra y falta de un grupo de control. ${ }^{12}$

La farmacéutica AstraZeneca iniciará una investigación clínica que evite a pacientes de coronavirus llegar a la intubación. El estudio en el que podría participar México se basa en la evaluación del fármaco acalabrutinib, un tratamiento que se aprobó este año para linfomas, el cual también se está evaluando en Estados Unidos y algunos países de Europa para el COVID-19. ${ }^{28}$
Los fármacos de reposicionamiento usados en las diferentes fases o espectros de la enfermedad se muestran en la Figura 1. El blanco terapéutico de cada fármaco se muestra en la Figura 2.

\section{FÁRMACOS DE REPOSICIONAMIENTO CONTRA EL VIRUS}

\section{Antivirales}

Remdesivir es un profármaco nucleótido intravenoso de un análogo de la adenosina. Remdesivir se une a la polimerasa del ARN viral dependiente de ARN e inhibe la replicación viral mediante la terminación prematura del ARN transcripción. Ha demostrado actividad in vitro contra el SARS-CoV-2.12,29

En un modelo de macaco Rhesus con infección por SARS-CoV-2, el tratamiento con remdesivir se inició poco después de la inoculación; los animales tratados con remdesivir tenían niveles más bajos de virus en los pulmones y menos daño pulmonar que los animales de control. ${ }^{12,30}$

Remdesivir está aprobado por la Administración de Alimentos y Medicamentos (FDA) para el tratamiento de COVID-19 en pacientes adultos y pediátricos hospitalizados. Remdesivir deberá ser administrado en un hospital o en un entorno de atención médica que pueda brindar un nivel de atención similar a un paciente hospitalizado. ${ }^{12}$

A partir del mes de marzo (2021), la COFEPRIS autorizó el uso de emergencia de remdesvir. La autorización de la COFEPRIS indica que el remdesivir es exclusivo para uso nosocomial de alta especialidad en casos tempranos de la COVID-19, aconsejando una vigilancia continua de la salud integral del paciente durante y después de su uso. ${ }^{31}$

\section{Favipiravir}

Actúa como un inhibidor de la ARN polimerasa. Favipiravir es metabolizado a favipiravir ribosiltrifosfato (favipiravir RTP) que inhibe selectivamente la ARN polimerasa (ARNdependiente de ARN polimerasa) del virus de la influenza previniendo la replicación viral. ${ }^{5,32,33}$

En un ensayo clínico sobre favipiravir para el tratamiento de COVID-19 realizado por la Clinical Medical Research Center of the National Infectious Diseases y el Third People's Hospital of Shenzhen se obtuvieron resultados prometedores en 80 pacientes (incluido el grupo experimental y el grupo de control) tratados con favipiravir; se observó mayor acción antiviral que con lopinavir/ritonavir. ${ }^{34}$ Su uso debe considerarse únicamente bajo protocolo de investigación y/o como uso compasivo. ${ }^{5}$ 


\section{Lopinavir/ritonavir}

La replicación de SARS-CoV-2 depende de la escisión de poliproteínas en un ARN dependiente ARN polimerasa y una helicasa. Dos proteasas son responsables de esta escisión: similar a la 3-quimotripsina proteasa (3CLpro) y proteasa similar a la papaína (PLpro). ${ }^{12}$

Solidarity fue un ensayo controlado aleatorio de etiqueta abierta que incluyó a pacientes hospitalizados con COVID-19 en 405 hospitales en 30 países. El estudio incluyó varios brazos; en un brazo, los participantes recibieron lopinavir/ritonavir. El grupo de control de este brazo incluyó a personas que estaban aleatorizados en el mismo sitio y en el mismo momento que podrían haber recibido lopinavir/ritonavir, pero recibieron el cuidado estándar en su lugar.12

No hubo diferencias significativas en la mortalidad hospitalaria con un análisis de dos brazos; 148 pacientes $(9.7 \%)$ en el grupo de lopinavir/ritonavir y 146 pacientes (10.3\%) en el grupo de atención estándar habían fallecido para el día 28. Entre los pacientes hospitalizados, lopinavir/ritonavir no disminuyó la mortalidad intrahospitalaria ni el número de pacientes que progresaron a ventilación mecánica en comparación con el estándar de atención. ${ }^{12}$ Los blancos terapéuticos que tienen estos fármacos se muestran en la Figura 2.

\section{OTROS FÁRMACOS}

\section{Anticoagulantes}

La infección por el nuevo síndrome respiratorio agudo severo coronavirus 2 (SARS-CoV-2) y el síndrome resultante COVID-19 se ha asociado con inflamación y un estado protrombótico, con aumento de la fibrina, los productos de degradación de la fibrina, el fibrinógeno y los dímeros-D. En algunos estudios las elevaciones en estos marcadores se han asociado con peores resultados clínicos. Varios estudios

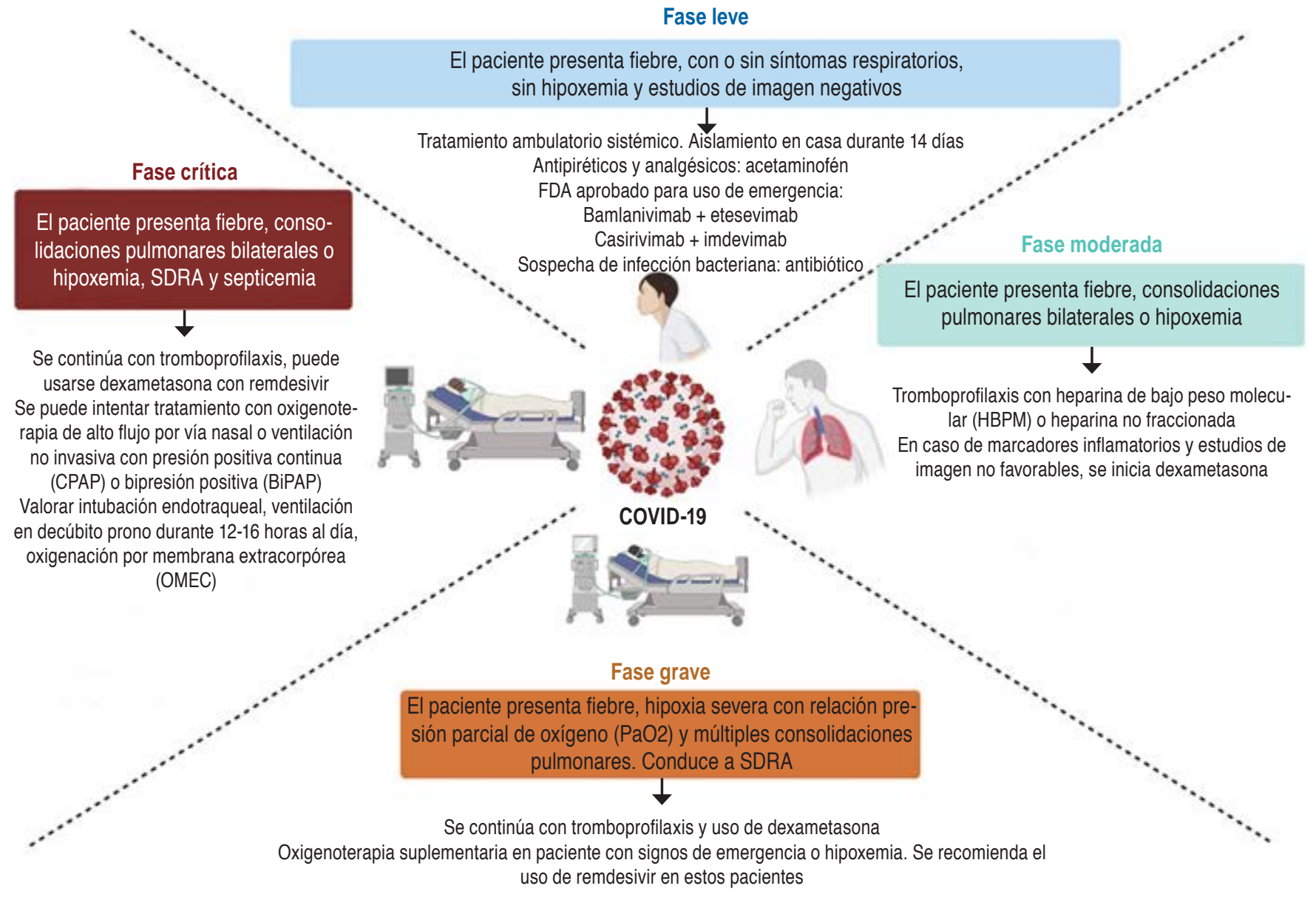

Figura 1: Fármacos usados de acuerdo a la fase de la enfermedad. La enfermedad COVID-19 se clasifica en cuatro fases (fase leve, fase moderada, fase grave y fase crítica). En esta imagen se presentan los síntomas de cada fase de la enfermedad y el tratamiento recomendado.

FDA = Administración de Alimentos y Medicamentos de los Estados Unidos, SDRA = Síndrome de dificultad respiratoria aguda. 


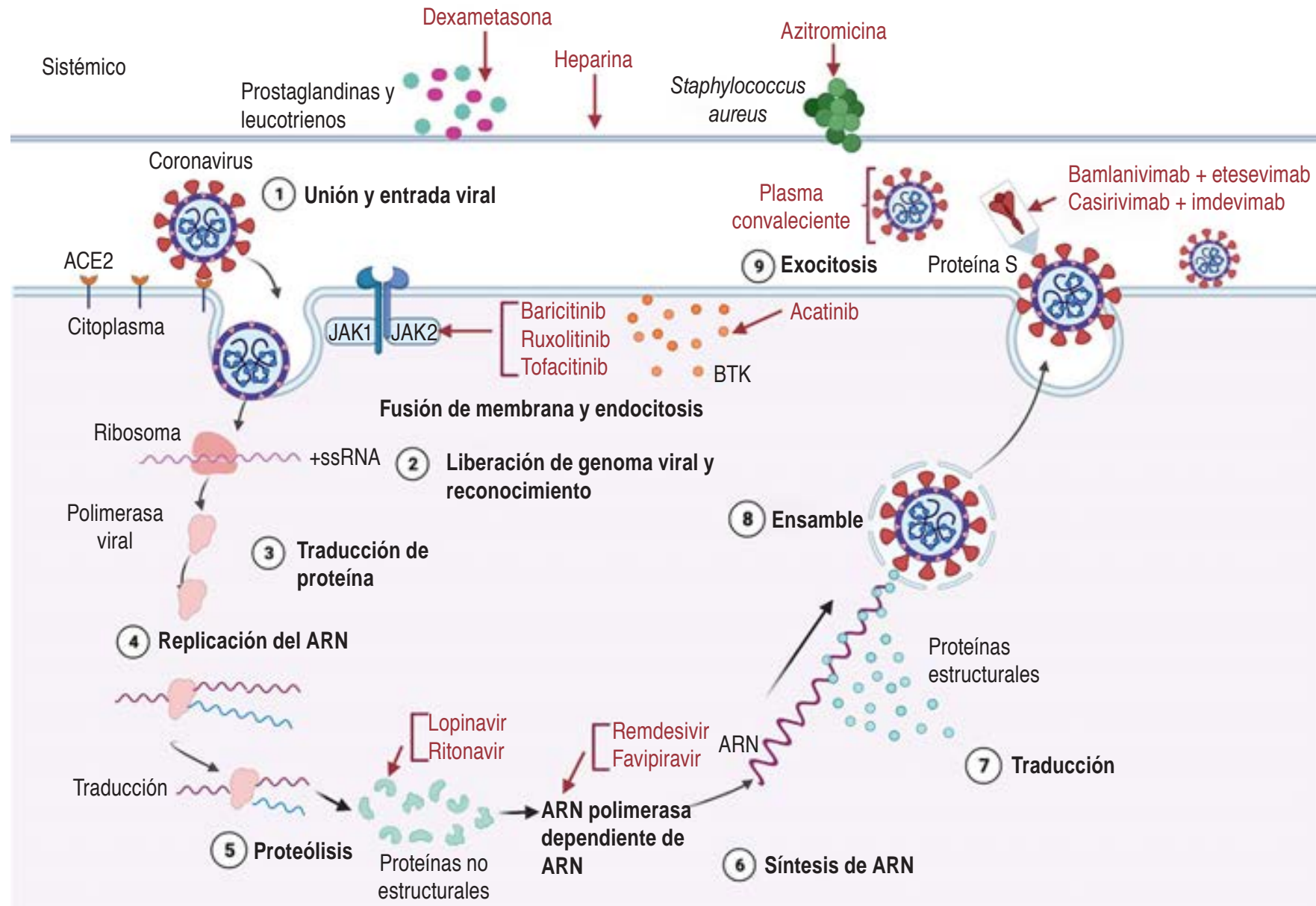

Figura 2: Ciclo de replicación del SARS-CoV-2 y sitios de acción de fármacos de reposicionamiento contra COVID-19. Representación del ciclo de replicación del SARS-CoV-2 y el blanco de acción de los fármacos que se encuentran en estudio para su uso de emergencia (en rojo).

+SSRNA (por sus siglas en inglés single stranded RNA, ARN de sentido positivo de una sola cadena); ssRNA (por sus siglas en inglés single stranded RNA, ARN de una sola cadena); ARN = ácido ribonucleico.

han informado incidencias variables de tromboembolismo venoso (TEV) en pacientes con COVID-19. Un metaanálisis de estudios en pacientes hospitalizados con COVID-19 encontró una prevalencia de TEV de $14.1 \% .^{12}$

Un metaanálisis realizado por un panel de directrices de la Sociedad Estadounidense de Hematología comparó la probabilidad de sangrado y resultados trombóticos en pacientes con COVID-19 tratados con dosis profilácticas anticoagulación versus en los tratados con anticoagulación de dosis intermedia o terapéutica. En pacientes críticamente enfermos, la anticoagulación de dosis intermedia o terapéutica se asoció con una menor probabilidad de embolia, pero mayor probabilidad de hemorragia grave. ${ }^{12}$

La enoxaparina es una heparina de bajo peso molecular (HBPM), con un peso molecular medio de aproximadamente 4.500 Daltons, en la que se han disociado las actividades antitrombóticas y anticoagulantes de la heparina estándar. El principio activo es la sal de sodio, posee una actividad anti-Xa elevada (alrededor de $100 \mathrm{UI} / \mathrm{mg}$ ) y una actividad débil antiIla o antitrombínica (aproximadamente $28 \mathrm{UI} / \mathrm{mg}$ ) con una relación entre estas dos actividades de 3.6. Estas actividades anticoagulantes están mediadas a través de la antitrombina III (ATIII) teniendo en humanos actividad antitrombótica. ${ }^{5}$

Todos los pacientes con COVID-19 hospitalizados requieren profilaxis antitrombótica, ya que todos cumplen con los criterios de Padua e Improve, que se asocia a un beneficio ya establecido con el uso de profilaxis. ${ }^{23}$

El uso de anticoagulantes se centra en la discusión sobre la dosis de heparina a utilizar con base en el riesgo trombótico, tomando en cuenta el riesgo hemorrágico, la funciones renal y hepática así como la cuenta plaquetaria. ${ }^{23}$

\section{Antibióticos}

Azitromicina es un antibiótico macrólido que pertenece al grupo de los azálidos. La molécula se sintetiza incorporando 
un átomo de nitrógeno al anillo de lactona de eritromicina A. El mecanismo de acción de azitromicina se basa en la inhibición de la síntesis de proteínas bacterianas por unión a la subunidad $50 S$ ribosómica y por tanto, la inhibición de la translocación de péptidos. ${ }^{5}$

En una serie de casos de 138 pacientes hospitalizados con COVID-19 confirmado, de los cuales 26\% recibió atención en la $\mathrm{UCl}$, les fueron administrados diversos tratamientos, incluidos oseltamivir (89.9\%), glucocorticoides (44.9\%), inhalación de oxígeno (76.8\%), ventilación mecánica no invasiva $(10.9 \%)$ y ventilación mecánica invasiva (12.3\%). También se administraron terapias antibacterianas, que incluyen moxifloxacino (64.4\%), ceftriaxona (24.6\%) y azitromicina (18.1\%). En el momento de la última observación, $34.1 \%$ de los pacientes habían sido dados de alta, $4.3 \%$ habían muerto y $61.6 \%$ seguían hospitalizados; la mediana de la estancia hospitalaria fue de 10 días (para quienes fueron dados de alta al momento del informe); sin embargo, la eficacia específica de la azitromicina no fue medida. ${ }^{5}$ Se recomienda utilizar cuando existe neumonía por organismos sensibles. ${ }^{5}$ El blanco terapéutico que tienen estos fármacos se muestra en la Figura 2.

\section{FÁRMACOS ESPECÍFICOS PARA EL TRATAMIENTO DEL SARS-COV-2 EN FASE EXPERIMENTAL}

A lo largo de esta pandemia se han realizado esfuerzos para encontrar un tratamiento específico y efectivo para tratar la COVID-19; sin embargo, a pesar de los grandes esfuerzos aún no existe una terapia específica contra esta enfermedad, aunque hay algunos candidatos que aún se encuentran en fase experimental como:

\section{Productos naturales bioactivos}

Se han descrito compuestos bioactivos que poseen propiedades anti-SARS-CoV, o que han demostrado ser eficaces contra el SARS-CoV, por lo que ha surgido interés en retomar estos posibles tratamientos contra el SARS-CoV-2. Un ejemplo son los derivados de quinonametido triterpeno Como inhibidores de 3CLpro del SARS-CoV, el 3CLpro del SARS-CoV, también llamado proteasa principal (Mpro), que tiene un papel importante en la replicación viral35,36 (Tabla 1).

\section{Control de la modificación del ARN específico del virus en COVID-19}

La metilación es un mecanismo de protección del ARN en los coronavirus, y desempeña un papel en la transcripción del ARN viral así como en la estabilidad, replicación y evasión de la respuesta inmunitaria del huésped. ${ }^{37}$
Los virus de ARN han desarrollado mecanismos para generar estructuras de coraza a través de la metilación, y tienen como función el empalme de preARNm, la exportación de ARNm, la estabilidad del ARN, el inicio de la traducción, y como mecanismo de escape del sistema inmunológico innato del huésped.

Los ARNm con el extremo 5' acorazado se producen a través de varios pasos, la (guanina-N7)-metiltransferasa (N7-MTasa) coronaviral tiene un papel en el procesamiento del ARN de los coronavirus para producir la estructura cap0 (m7GpppN). Esta enzima se ha propuesto como blanco para los nuevos fármacos antivirales. ${ }^{37}$

\section{Enzalutamida}

La enzalutamida es un inhibidor del receptor de andrógenos $(A R)$, se une a $A R$, reduce la eficiencia de su translocación desde el citoplasma al núcleo y altera la vía de señalización mediada por AR. ${ }^{38}$

La serina proteasa transmembrana 2 (TMPRSS2) desempeña un papel esencial en la entrada del SARS-CoV-2 en las células del huésped. Se ha demostrado que la glicoproteína de espiga (S) del SARS-CoV-2 y su receptor, la enzima convertidora de angiotensina 2 (ACE2) participan en la entrada del SARS-CoV-2 a las células del hospedero, y la proteína $S$ del SARS-CoV-2 es procesada por la TMPRSS2. Se ha descrito que tanto el SARS-CoV-2 como el SARS-CoV, incluso el virus de H1N1, también emplean la TMPRSS2 para la entrada viral.

Por lo cual, la enzalutamida se ha propuesto como un prometedor fármaco de reposicionamiento para inhibir la infección por el SARS-CoV-2e, ya se han iniciado varios ensayos clínicos para evaluar la eficacia terapéutica de la enzalutamida en pacientes con COVID-19 (ClinicalTrials. gov; NCT04475601 y NCT04456049). Aunque la enzalutamida inhibe significativamente la infección por SARS-CoV-2 en células de cáncer de próstata, aún falta por investigar si es efectivo en otro tipo de células.

\section{MK-4482 (EIDD-2801)}

Es un profármaco biodisponible del análogo del nucleósido de citidina EIDD-1931. EIDD-1931 se identificó como un inhibidor de amplio espectro contra influenza A y el virus sincicial respiratorio; funciona como un mutágeno de ARN que lleva a un codón de terminación de la cadena. Se ha demostrado que el EIDD-1931 tiene una potente actividad contra el SARS-CoV-2 in vitro en células epiteliales. ${ }^{39,40}$

Se ha reportado que si el inicio del tratamiento con MK-4482 es dentro de las 12 horas siguientes a una exposición productiva, es decir, que dé lugar a una infección. Se reduce significativamente la replicación del SARS-CoV-2 
y el daño pulmonar. El MK-4482/EIDD-2801 fue eficaz y bien tolerado por vía oral contra el SARS-CoV-2, ya que reduce la carga viral de las vías respiratorias superiores y, al igual que lo observado con la administración del CS-5734 (remdesivir), es más eficaz cuando se administra en una fase temprana tras la infección. Por lo cual el MK-4482 debería considerarse como una aplicación oral posexposición para el SARS-CoV-2. ${ }^{39,40}$

\section{CONCLUSIÓN}

El tratamiento para la COVID-19 ha tenido una larga evolución que ha dependido de los nuevos estudios y avances que se obtienen de la investigación de esta enfermedad. Con base en los datos se sabe que el régimen actual de fármacos ha mostrado una eficacia variable hacia la mejoría de la enfermedad así como para evitar complicaciones asociadas a ésta, pero nula o marginal respuesta para prevenir los casos graves de la enfermedad, por lo que se debe impulsar el estudio de nuevos fármacos que podrían resultar beneficiosos para la salud de los pacientes y disminuir la mortalidad causada por el SARS-CoV-2 en el futuro. Aunque los fármacos de reposicionamiento son de gran utilidad para tratar nuevas pandemias, se requiere contar con nuevos tratamientos específicos contra el virus SARS-CoV-2 para acelerar su aplicación clínica.

\section{REFERENCIAS}

1. Juarez M,Schcolnik-Cabrera A, Dueñas-Gonzalez A. The multitargeted drug ivermectin: from an antiparasitic agent to a repositioned cancer drug. Am J Cancer Res [Internet]. 2018;8(2):317-331. Available in: http://www.ncbi.nlm. nih.gov/pubmed/29511601\%0Ahttp://www. pubmedcentral.nih.gov/articlerender.fcgi?artid=PMC5835698

2. Dominguez-Gomez G, Chavez-Blanco A, Medina-Franco JL, SaldivarGonzalez F, Flores-Torrontegui Y, Juarez M, et al. Ivermectin as an inhibitor of cancer stem-like cells. Mol Med Rep. 2018;17(2):3397-3403.

3. OMS. Manejo clínico de la COVID-19. Organización Mundial de la Salud [Internet]. 2020;(5):1-68. Available in: https://apps.who.int/iris/ bitstream/handle/10665/332638/WHO-2019-nCoV-clinical-2020.5spa.pdf

4. ARDS Definition Task Force, Ranieri VM, Rubenfeld GD, Thompson $\mathrm{BT}$, Ferguson ND, Caldwell, E, Fan E, et al. Acute respiratory distress syndrome: the Berlin Definition. JAMA [Internet]. 2012;307(23):25262533. Available in: https://doi.org/10.1001/jama.2012.5669

5. De DESDELAC, Subsecretar X, Prestaci DE, Servicios DE, Direcci I, Medicamentos DE. Guía Farmacoterapéutica de Medicamentos empleados en el tratamiento de pacientes con enfermedad COVID-19. 2020.

6. Wang MY, Zhao R, Gao LJ, Gao XF, Wang DP, Cao JM. SARS-CoV-2: structure, biology, and structure-based therapeutics development. Front Cell Infect Microbiol. 2020;10:587269.

7. Bartoli A, Gabrielli F, Alicandro T, Nascimbeni F, Andreone P. COVID-19 treatment options: a difficult journey between failed attempts and experimental drugs. Intern Emerg Med [Internet]. 2021;16(2):281-308. Available in: https://doi.org/10.1007/s11739-02002569-9

8. Mohamadian M, Chiti H, Shoghli A, Biglari S, Parsamanesh N, Esmaeilzadeh A. COVID-19: virology, biology and novel laboratory diagnosis. J Gene Med. 2021;23(2):e3303.

9. Mousavizadeh L, Ghasemi S. Genotype and phenotype of COVID-19: Their roles in pathogenesis. J Microbiol Immunol Infect [Internet]. 2021;54(2):159-163. Available in: https://doi.org/10.1016/j. jmii.2020.03.022

10. Samudrala PK, Kumar P, Choudhary K, Thakur N, Wadekar GS, Dayaramani $\mathrm{R}$, et al. Virology, pathogenesis, diagnosis and in-line treatment of COVID-19. Eur J Pharmacol. 2020;883:173375.

11. Magro G. SARS-CoV-2 and COVID-19: What are our options? Where should we focus our attention on to find new drugs and strategies? Travel Med Infect Dis. 2020;37:101685.

12. Coronavirus Disease 2019 (COVID-19) Treatment Guidelines. National Institutes of Health. 2021.

13. SSA. Uso de plasma convaleciente para atención de pacientes con COVID-19. 2020;2(195).

14. Weinreich DM, Sivapalasingam S, Norton T, Ali S, Gao H, Bhore R, et al. REGN-COV2, a neutralizing antibody cocktail, in outpatients with Covid-19. N Engl J Med. 2021;384(3):238-251.

15. Wang Y, Zhang L, Sang L, Ye F, Ruan S, Zhong B, et al. Kinetics of viral load and antibody response in relation to COVID-19 severity. $J$ Clin Invest. 2020;130(10):5235-5244.

16. Dougan M, Nirula A, Gottlieb RL, Azizad M, Mocherla B, Chen P, et al. Bamlanivimab+etesevimab for treatment of COVID-19 in highrisk ambulatory patients. [Internet]. 2021. Available in: https://www. croiconference.org/wp-content/uploads/sites/2/ resources/2021/ vCROI-2021-Abstract-eBook.pdf

17. Federal Drug Administration. Fact Sheet for Health Care Providers. 2020;1-36. Available in: https://pi.lilly.com/eua/bamlanivimab-euafactsheet-hcp.pdf

18. FDA. Emergency use authorization (EUA) of casirivimab and imdevimab. 2019;1-36.

19. Phase 3 trial shows REGEN-COV (casirivimab with imdevimab) antibody cocktail reduced hospitalization or death by $70 \%$ in non-hospitalized COVID-19 patients. [Internet]. 2021. Available in: https://investor.regeneron.com/news-releases/news-releasedetails/phase-3-trialshows-regen-covtm-casirivimab-imdevimabantibody

20. RECOVERY Collaborative Group, Horby P, Lim WS, Emberson JR, Mafham M, Bell JL, Linsell L, et al. Dexamethasone in hospitalized patients with Covid-19. N Engl J Med. 2021;384(8):693-704.

21. Arabi YM, Mandourah Y, Al-Hameed F, Sindi AA, Almekhlafi GA, Hussein MA, et al. Corticosteroid therapy for critically ill patients with middle east respiratory syndrome. Am J Respir Crit Care Med. 2018;197(6):757-767.

22. Lansbury L, Rodrigo C, Leonardi-Bee J, Nguyen-Van-Tam J, Lim WS. Corticosteroids as adjunctive therapy in the treatment of influenza. Cochrane Database Syst Rev. 2019;2(2):CD010406.

23. Recomendaciones para el tratamiento de la infección por SARSCoV-2, agente causal de COVID-19. Harefuah. 2020;102(1):40-41.

24. Cao Y, Wei J, Zou L, Jiang T, Wang G, Chen L, et al. Ruxolitinib in treatment of severe coronavirus disease 2019 (COVID-19): a multicenter, single-blind, randomized controlled trial. J Allergy Clin Immunol. 2020;146(1):137-146.e3. Available in: https://www.ncbi.nlm. nih.gov/pubmed/32470486 
25. Ovilla-Martínez R, De la Peña-Celaya JA, Báez-Islas PE, Del Bosque-Patoni C, Guzmán-Bouilloud NE, Rodríguez-Sandoval R, et al. Tratamiento exitoso con ruxolitinib en un caso de neumonía por SARS-CoV-2 en México. Med Int Mex [Internet]. 2020;36(5):740-744. Available in: https://doi.org/10.24245/mim. V36i5.4372

26. Migita K, Izumi Y, Jiuchi Y, Kozuru H, Kawahara C, Izumi M, et al. Effects of Janus kinase inhibitor tofacitinib on circulating serum amyloid $A$ and interleukin- 6 during treatment for rheumatoid arthritis. Clin Exp Immunol. 2014;175(2):208-214.

27. Salgado LA. Pfizer avanza en la batalla contra el COVID-19 en múltiples frentes. Codigo F [Internet]. 2020. Available: https://codigof.mx/pfizeravanza-en-la-batalla-contra-el-covid-19-en-multiples-frentes/

28. Rodríguez A. AstraZeneca sube inversión en México [Internet]. 2020. Available in: https://www.elfinanciero.com.mx/empresas/astrazenecasube-inversion-en-mexico/

29. Wang M, Cao R, Zhang L, Yang X, Liu J, Xu M, et al. Remdesivir and chloroquine effectively inhibit the recently emerged novel coronavirus (2019-nCoV) in vitro. Cell Res. 2020;30(3):269-271.

30. Williamson BN, Feldmann F, Schwarz B, Meade-White K, Porter DP, Schulz J, et al. Clinical benefit of remdesivir in rhesus macaques infected with SARS-CoV-2. Nature. 2020;585(7824):273-276. doi: 10.1038/s41586-020-2423-5.

31. Garrod M. La Cofepris autoriza el uso de emergencia del remdesivir en México. [Internet]. 2021. Available in: https://codigof.mx/la-cofeprisautoriza-el-uso-de-emergencia-del-remdesivir-en-mexico/

32. Delang L, Abdelnabi R, Neyts J. Favipiravir as a potential countermeasure against neglected and emerging RNA viruses. Antiviral Res [Internet]. 2018;153:85-94. Available in: https://doi. org/10.1016/j.antiviral.2018.03.003

33. Furuta Y, Komeno T, Nakamura T. Favipiravir (T-705), a broad spectrum inhibitor of viral RNA polymerase. Proc Jpn Acad Ser B
Phys Biol Sci [Internet]. 2017;93(7):449-463. Available in: https:// www.ncbi.nlm.nih.gov/pmc/articles/PMC5713175/pdf/pjab-93-449

34. Dong L, Hu S, Gao J. Discovering drugs to treat coronavirus disease 2019 (COVID-19). Drug Discov Ther. 2020;14(1):58-60.

35. Krishna G, Pillai VS, Veettil MV. Approaches and advances in the development of potential therapeutic targets and antiviral agents for the management of SARS-CoV-2 infection. 2020; 885, 173450. Available in: https://doi.org/10.1016/j.ejphar.2020.173450

36. Ryu YB, Park SJ, Kim YM, Lee JY, Seo WD, Chang JS, et al. SARS-

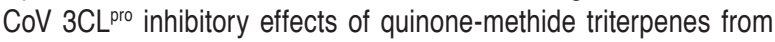
Tripterygium regelii. Bioorganic Med Chem Lett. 2010;20(6):18731876. Available from: https://doi.org/10.1016/j.bmcl.2010.01.152

37. Asai A, Konno M, Ozaki M, Otsuka C, Vecchione A, Arai T, et al. COVID-19 drug discovery using intensive approaches. Int J Mol Sci. 2020;21(8):2839. Available in: https://doi.org/10.3390/ ijms21082839

38. Li F, Han M, Dai P, Xu W, He J, Tao X, et al. Distinct mechanisms for TMPRSS2 expression explain organ-specific inhibition of SARSCoV-2 infection by enzalutamide. Nat Commun. 2021;12(1). Available from:https://doi.org/10.1038/s41467-021-21171-x

39. Rosenke K, Hansen F, Schwarz B, Feldmann F, HaddockE, Rosenke $\mathrm{R}$, et al. Orally delivered MK-4482 inhibits SARS-CoV-2 replication in the Syrian hamster model. Nat Commun. 2021;12(1). Available from: https://doi.org/10.1038/s41467-021-22580-8

40. Cox RM, Wolf JD, Plemper RK. Therapeutic MK-4482/EIDD-2801 Blocks SARS-CoV-2 transmission in ferrets. Nat Microbiol. 2021;6:1118. Available in: https://doi.org/10.1038/s41564-020-00835-2

Conflicto de intereses: Los autores declaran no tener conflicto de intereses. 